\title{
For the Field
}

\section{Game On! Reflections of a Board Game Librarian: An Examination and Application of Non-Traditional Collections and Recreational Play in the Academic Library}

Libraries have traditionally existed for the purpose of providing information to patrons, generally in the form of traditional print collections consisting of books and periodicals. The role of the library, however, has shifted in recent years. Several trends have emerged, including: the use and acceptance of electronic resources and the resultant decline in the circulation of print materials, a reduction in reference services, and, in the case of academic libraries, a major shift from independent learning towards collaborative learning (Gayton, 2008). Another key trend is becoming more prevalent in libraries--non-traditional collections.

This article will briefly introduce non-traditional library collections, illustrate personal experiences and best practices as a board game librarian, and highlight implications of collecting non-traditional items and programming during the COVID-19 pandemic.

\section{Non-Traditional Library Collections}

Put simply, non-traditional collections are those that extend beyond traditional items, including seed libraries/seed shares, crafting kits, tools, sporting and fitness equipment, science kits (e.g., Arduino, Raspberry Pi), musical instruments, puzzles, and board games. Libraries collect these items for several reasons: 
- To attract and engage new patrons, or traditionally hard-to-reach populations, with library collections and services (Edwards, 2018; Michnik \& Eriksson, 2014).

- To contribute to a particular library goal or objective (Michnik \& Eriksson, 2014).

- To promote an environment of social inclusivity, equal access, and equity (Michnik \& Eriksson, 2014; Söderholm, 2015).

The literature indicates that both libraries and their patrons benefit from nontraditional collections. Libraries benefit by increasing patron traffic, which in turn may lead to more engagement with traditional collections and services offered by the library (Edwards, 2018), as well as increased funding. Some collections may make the library more attractive to community members by "increasing a sense of well-being and comfort in the library" (Michnik \& Eriksson, 2014, p. 167). Non-traditional collections also provide library staff with more tools to facilitate library activities, which assists in the achievement of library goals (Michnik \& Eriksson, 2014). For instance, a library that loans out media equipment, such as laptops or tablets, may also benefit staff who require the technology for managing and administering library programs. Finally, libraries may develop community partnerships that assist in providing additional resources and programming (Charles, 2012). For example, the University of Prince Edward Island (UPEI) has partnered with the Sidewalk Astronomers of Charlottetown and local libraries to create a borrowable collection of telescopes, along with instructional and technical support (University of Prince Edward Island, n.d.).

To illustrate some of the benefits experienced by patrons, Söderholm (2015) examined the reasons why tools were borrowed from the Berkley Tool Lending Library and the benefits that were attained. Patrons accessed the collection for a variety of 
reasons, including cost, frequency of use, and storage considerations. With these factors in mind, Söderholm discovered that borrowing tools was a form of enablement for patrons. Wider access to tools assists patrons in performing tasks they previously could not accomplish on their own. The tool library provided opportunities for patrons to develop their skill sets, and in some cases, assist with self-employment by eliminating or reducing financial barriers. Michnik \& Eriksson (2014) also touch on the idea of equity and state that non-traditional collections can be used by anyone "regardless of social and economic status" (p. 167). Non-traditional collections provide a social dimension which allows patrons to meet and collaborate with like-minded patrons and library staff (Söderholm, 2015). Furthermore, patron engagement with library staff may help eliminate or reduce instances of library anxiety.

What follows is an examination of how a board game collection and program at a community college academic library came to be, along with considerations and best practices learned from first-hand experience.

\section{Board Games in the Library}

Board games are well-suited to libraries and educational institutions as they provide students with a "strong foundation for learning" (Mayer \& Harris, 2010, p. 11) through recreational play. On top of the existing benefits of non-traditional collections, board games engage students on a familiar level in order to "reinforce critical social and life skills" (Mayer \& Harris, 2010, p. 12), including inquiry, information sharing, communication, problem solving, and critical thinking. These skills are often included in the mission and vision statements of educational institutions, which make academic and school libraries ideal venues for hosting board game collections and programs. 
I am a part-time reference specialist and board game librarian (an unofficial title) at a community college academic library. The library has a history of collecting nontraditional items, which allows students to borrow video games, video game consoles, calculators, and media equipment (e.g., video cameras, computers, chargers). The library also provides 3D-printing and laser cutting services to students and will expand its makerspace capabilities in the future. Having recently amalgamated with the learning centre, which offers math, science, and writing assistance, the library has become a learning commons that emphasizes out-of-classroom learning, social exchanges, and collaborative approaches to learning (Gayton, 2008).

With a background in project management and research in another form of nontraditional library collection - tabletop role-playing games - I applied my knowledge to the creation and management of a board game collection and program. At the time of writing, I have managed a collection of over 25 games for nearly two years.

\section{Considerations \& Practical Application}

This section details some considerations for creating a non-traditional collection, as well as highlights my experiences in creating and managing a board game collection.

\section{Needs Assessment}

This involves aligning the collection with the library's organizational values and surveying the needs of the community. To be successful, the development of a nontraditional collection must contribute to the values and goals of the library (Michnik \& Eriksson, 2014). A typical survey method is environmental scanning, which examines several factors: what the demographics of the library are, who the users of the collection will be, and what other libraries or institutions can be used as benchmarks. 
Practical Application: The collection is closely aligned with library values, namely: improvement of the social and technical skills of students, provision of a friendly and safe library environment for students, attraction of non-library users to the library, and collaborative learning. The key demographics of the library consists of a large population of international students. At this institution, these students tend to be more likely to engage with programming over their domestic peers. As a result, languageindependent games, like Tsuro, are popular.

\section{Collection Development}

After deciding who the primary users of the collection may be, the next step is to identify which items to collect. This involves developing selection and evaluation criteria to determine the effectiveness of the collection. This may also include creating community partnerships and asking for donations.

Practical Application: Due to budgetary constraints, games are purchased in increments (about three to four items at a time). The websites Games \& Gaming Round Table (American Library Association), Board Game Geek (BGG), and the League of Librarian Gamers - ALA GameRT social media page was consulted for game recommendations (see Helpful Resources in Additional Resources). Games are also selected based on several criteria from BGG:

- Number of players. In alignment with collection goals, games are selected that can be played with two or more players to encourage player interaction.

- User ratings. Games with higher average user ratings and comments are selected.

- Playing time. Games are selected that can be played in 45 minutes or less, so students are able to play several games during programming. 
- Weight. Refers to the board game's complexity, or how difficult a game is to understand. For the purposes of the library's collection, lighter weight games are generally preferred.

The collection is being further developed based on students' preferred game mechanics and complexity levels. This information is gathered during programming through student observation and an anonymous five question survey (see Game Night Feedback in Additional Resources for a sample).

\section{Circulation, Preservation, and Storage}

Will the collection be circulating or non-circulating? Are there any requirements for the preservation and storage of the items? This step may also include plans for cataloguing, inventorying, and replacing items.

Practical Application: The collection is non-circulating and is stored in a staff-only area of the library unless requested by a student or brought out to the floor for programming. Based on recommendations by Robson et al (2018), three key preservation techniques are used:

1) Clear book tape is used to preserve the corners of game boxes and rulebook spines.

2) An inventory of all game components is included on the underside of each game box lid.

3) Game components (e.g., dice, pawns, cubes) are bagged and clearly labelled.

RFID tags are also affixed to each box to prevent games from leaving the library. Students, however, are actively encouraged to sign out a game to play within the library, using a simple manual tracking form requiring a student ID. 


\section{Programming}

The best way to ensure the success of a non-traditional collection is to tie it into library programming. Other considerations include the duration and frequency of programming, marketing, and partnerships.

Practical Application: The original plan was to host a monthly board game night for a duration of two hours; however, students felt that the duration was too short and they wanted more frequent events. Based on this feedback, program duration was increased to three hours and frequency was increased to twice a month. Games from my personal collection are introduced to enhance or fill any gaps in the collection and to see how well certain games or game mechanics were received by students. This helps to determine which games should be considered for the collection. Marketing includes physical posters and flyers, which are distributed throughout the college, social media posts, word-of-mouth, and on-campus partnerships (international centre and student association).

\section{Benefits \& Challenges of the Collection}

\section{Benefits}

- Teaching and playing games with students is an excellent opportunity to dispel library anxiety and make students feel comfortable accessing the library and its services. I noticed that several attendees of the library's bi-monthly board game nights became regulars in the library.

- The collection enables students to access numerous board games that they may not have had access to. Board games can be costly, and the collection provides a way to play without cost or the demand of storage. 
- Students can socialize with each other during programming which provides valuable opportunities to improve upon language, global citizenship, problem solving, critical thinking, and social intelligence skills.

\section{Challenges}

- Game nights are easier to manage with volunteers, which are not always available.

- Working with limited resources (e.g., finances, marketing) and attempting to implement a board game program resulted in difficulties with student attendance.

- The greatest challenge of all, however, began in March 2020 with the COVID-19 pandemic. All board game nights were cancelled, and the collection suspended.

\section{Gaming in Pandemic Times}

This section highlights several implications the pandemic has on library collections and programming, including how libraries have adapted services and programming online.

\section{Pandemic Implications}

- The library as a physical space is either no longer available to patrons, or severely limited to curb the spread of COVID-19. This has impacted many patrons, including families, children, students, and marginalized populations.

- Libraries have had to shift from circulating print and electronic collections towards a more e-focused strategy to support patrons and distance learning. This shift towards enhanced e-resources has created new opportunities for meeting patrons where they are; however, this has also created barriers to access for patrons who do not have access to high-speed internet and technology. 
- More library programming has been made available online, including virtual storytimes, book launch events, and board game programming.

\section{Virtual Board Game Programs}

Over the course of 2020 and into 2021, libraries have adapted board game programs to online environments to cater to the needs of patrons. Odum Library, an academic library at Valdosta State University, is one such library to successfully translate their in-person board game programming to an online environment. Odum Library has relied on technology, such as Discord- a voice over IP (VoIP) platform- to share gaming resources, host programming (Costello, 2021), and foster a sense of community among patrons and library staff. Programming includes trivia nights, virtual escape rooms, and game nights using board game platforms/simulators and other software, such as Jackbox Games (2021). Attendance to these events has lessened compared to inperson programming; however, students who attend enjoy and appreciate the virtual programming (Costello, 2021), which has become a unique tool in combatting the stresses of social isolation (Kriz, 2020).

\section{Online Platforms \& Services}

As illustrated by Odum Library, one of the most common platforms for hosting virtual programming is Discord; however, other platforms, such as Zoom and Microsoft Teams, are also popular.

Board game simulators are common tools for online programming and each platform typically offers some free content. Yucata.de and Boiteajeux.net are entirely free, feature no real-time play, offer almost exclusively classic games, and possess a very low learning curve. Unofficial clones for some games, such as Colonist (Catan), as 
well as official versions of popular board games (․ㅡinion, $\underline{\text { Codenames) }}$ may also be appropriate options (Pappas \& Bebo, 2020). Perhaps two of the best board game simulators are Board Game Arena and Tabletopia (see Table 1 below for a comparison).

Table 1: Online Board Game Platforms

\begin{tabular}{|c|c|}
\hline Board Game Arena & Tabletopia \\
\hline $\begin{array}{l}\text { A free account grants access to most } \\
\text { games. } \\
\text { A premium account ( } \$ 34.80 \mathrm{CAD} \\
\text { annually) grants access to all premium } \\
\text { games, allows the account to host } \\
\text { tables and tournaments, and includes } \\
\text { integrated video/voice chat. } \\
\text { - } \text { Access to } 263 \text { games. } \\
\text { Contains Al to help with rules (low } \\
\text { learning curve). } \\
\text { - Synchronous and asynchronous play. }\end{array}$ & $\begin{array}{l}\text { - A free account grants access to most } \\
\text { games. } \\
\text { - Paid accounts range from } \$ 4.99-\$ 9.99 \\
\text { USD/month. } \\
\text { - Access to } 1,500+\text { board games, } \\
\text { including Kickstarter exclusives. } \\
\text { - Physics engine with no Al component } \\
\text { - Knakes for a steep learning curve. } \\
\text { and rules required before play. }\end{array}$ \\
\hline
\end{tabular}

\section{Final Thoughts}

Non-traditional library collections provide meaningful benefits to libraries and patrons.

The ultimate goals of non-traditional collections are to contribute to library objectives and provide equitable access and opportunities to patrons. The board game collection I created and manage fulfills the needs of the academic library, as well as provides a socially inclusive environment for students. The COVID-19 pandemic has temporarily paused collection and program activities; however, this article has explored several short-term impacts of the pandemic and how libraries have adapted. I fully expect that 
library staff will continue to implement many of these short-term strategies and adaptations in the future to expand access for patrons.

\section{Carlie Forsythe}

Forsythe, C. (2021). Game on! Reflections of a board game librarian: An examination and application of non-traditional collections and recreational play in the academic library. Emerging Library \& Information Perspectives, 4, 143-156. https://doi.org/10.5206/elip.v4i1.13442

\section{References}

Charles, C. (2012). Can I check this out?: Circulating collections beyond books, CDs, and DVDs. Public Libraries Online. http://publiclibrariesonline.org/2012/11/can-icheck-this-out-circulating-collections-beyond-books-cds-and-dvds/

Costello, D. (2021). Georgia library spotlight - Valdosta State University, Odum Library, board game collection \& gaming program. Georgia Library Quarterly, 58(1), 1-2.

Edwards, E. A. (2018). "Non-traditional” library services: Expanding the Library's offerings while increasing community engagement. ILA Reporter, XXXVI(6). https://www.ila.org/publications/ila-reporter/article/98/non-traditional-libraryservices-expanding-the-library-s-offerings-while-increa

Gayton, J. T. (2008). Academic libraries: "Social" or "communal?" The nature and future of academic libraries. The Journal of Academic Librarianship, 34(1), 60-66. https://doi.org/10.1016/j.acalib.2007.11.011

Kriz, W. C. (2020). Gaming in the time of COVID-19. Simulation \& Gaming, 51(4), 403410. https://doi.org/10.1177/1046878120931602 
Mayer, B., \& Harris, C. (2010). Libraries got game. American Library Association.

Michnik, K., \& Eriksson, C. (2014). Non-traditional library collections - in digital and other worlds. Interlending \& Document Supply, 42(4), 165-170. https://doi.org/10.1108/ILDS-09-2014-0043

Pappas, J., \& Bebo. (2020, July 28). Whose turn is it, anyway? Online board gaming and libraries [Webinar]. Web Junction. https://learn.webjunction.org/course/view.php?id=493

Robson, D., Phillips, J., \& Guerrero, S. (2018). Don't just roll the dice: Simple solutions for circulating tabletop game collections effectively in your library. Library Resources \& Technical Services, 62(2), 80-90. https://doi.org/10.5860//rts.62n2.80

Söderholm, J. (2015). Borrowing tools from the public library. Journal of Documentation, 72(1), 140-155. https://doi.org/10.1108/JD-01-2015-0010

University of Prince Edward Island. (n.d.). Library telescopes. https://projects.upei.ca/astronomy/library-telescopes/ 


\section{Additional Resources}

\section{Helpful Resources}

- The Games \& Gaming Round Table contains ample resources for librarians, including program and collection development recommendations.

- League of Librarian Gamers provides an inclusive environment for librarians and library-adjacent individuals to discuss and share resources.

- BoardGameGeek is an online resource and community that consists of a large database of board and card games. Within this database, each game has its own entry with information about the game, including number of players, complexity levels, images, forums, and user reviews. BGG has also created its own classification system to describe and tag game mechanics.

- Watch it Played is a YouTube channel dedicated to teaching the rules of popular board games in an accessible way. This resource is great to not only learn rules, but to also determine if a particular game may be a good fit for your library.

- Crowdfunding platforms, like Kickstarter, are great sources of new and upcoming games with the option of financially backing campaigns. 


\section{GAME NIGHT FEEDBACK}

Event: $\quad$ Board Game Night

Date:

Location:

1. How many games did you play?
1
ㄴ 2
$\square 3$
$\square 4$
ㄷ 5+

2. What was/were your favourite game(s) played tonight? (Select all that apply)
口 Zombie Fluxx
- Sushi Go
口 5-Minute Dungeon
- Carcassonne
$\square \quad$ King of Tokyo
$\square \quad$ Forbidden Desert
I don't have a favourite.

3. What was your level of enjoyment tonight?
1
$\square 2$
$\square 3$
$\square 4$
$\square 5$
$1=$ Very Low
$3=$ Neutral
$5=$ Very High

4. Would you attend another game night at $?$

Yes, definitely!

$\square \quad$ Maybe.

$\square \quad$ No, it wasn't for me.

$\square \quad$ Other (explain):

5. Do you have any suggestions for improvement? 